\title{
Residual Stresses Distributions in Grinding of 3J33 Maraging Steel with Miniature Electroplated CBN Wheel
}

\author{
Shouguo Shen, Beizhi Li, and Weicheng Guo \\ College of Mechanical Engineering, Donghua University, Shanghai 201620, China.
}

\begin{abstract}
It is well known that the residual stresses on the ground surface and the subsurface can influence the service quality of a component, such as fatigue life, tribological properties, and distortion. In this paper, an experimental investigation was conducted to determine the effects of grinding force, temperature and grinding conditions, such as grinding speed, workpiece speed and grinding depth, on the surface and in-depth residual stresses distributions induced by grinding of $3 \mathrm{~J} 33$ maraging steel with the miniature electroplated CBN Wheels. The results show that a 'hook' shaped residual stress profile is generated with the maximum compressive stresses occur at the depth of 3-14 $\mu \mathrm{m}$ below the ground surface. There is a good correlation between residual stress and cutting force, but the trend related to grinding temperature is not obvious. The main grinding parameters affecting the residual stresses distributions is grinding speed, while the workpiece speed and grinding depth have the least effect.
\end{abstract}

\section{Introduction}

$3 \mathrm{~J} 33$ maraging steel (equivalent to $18 \mathrm{Ni}$ (250) maraging steel) is a special class of high-strength steel which differs from conventional steels in the way that they are hardened by metallurgical reaction that does not involve carbon. Maraging steels are a class of ultrahigh strength martensitic steels. They exhibit a unique combination of properties that include ultrahigh strength and excellent fracture toughness. These steels are therefore important candidate materials for critical applications such as rocket motor cases, submarine hulls, connecting rods, landing gears and bridge layer tanks [1].

The final processing stage of many high-strength steel components for stress-critical applications in the automotive and aerospace industries involves abrasive grinding to the required component shape [2]. In assessing the process performance, residual stress plays an important role for its effects on the fatigue life, corrosion resistance, and part distortion [3]. For a given material, the worse the grinding conditions, in general, the more likely it is to cause thermal damage to the workpiece.Therefore, controlled-stress grinding is needed for an optimum combination of high surface integrity and high material removal rates [2].

Influences of grinding parameters on residual stresses have been studied in terms of wheel speed, workpiece speed, cutting depth, material removal rate, wheel characteristics, dressing conditions, and material conditions [4]. It is recommended that generation of residual stress is the result of various mechanical and thermal effects occurring at the machined surface region during grinding. Low and compressive residual stress after grinding is an important requirement for surface integrity of stress sensitive components [5].

Ding et al. [5] found that the values of the compressive stresses are decreased with the increase in depth of cut in creep feed grinding with brazed CBN Wheels. Chen et al. [4] observed that ultra-high-speed grinding can obtain lower surface residual tensile stress than high-speed grinding. Brinksmeier et al. [6] concluded that the increase in depth of cut and/or grinding speed increase the magnitude of tensile residual stresses. Sosa et al. [7] studied residual stresses induced by grinding on thin wall ductile iron plates. They proposed that residual stresses increased with depth of cut and decreased with work speed. Fathallah et al. [8] observed that the amplitudes of the compressive surface residual stresses generated in high-speed grinding (i.e., 60-260 m/s) with CBN wheels are much higher than those produced in conventional speed grinding (i.e., 22 $\mathrm{m} / \mathrm{s}$ ) with alumina wheels. Hamdi et al. [9] used a finite element thermo-mechanical model to calculate the residual stress induced by a surface grinding process of AISI 52100 steel. They found that tensile surface residual stress along the grinding direction becomes larger when a greater wheel speed of $30-120 \mathrm{~m} / \mathrm{s}$ is applied.

Although there have been many discussions regarding the influence of grinding processes parameters on the grinding residual stresses, the amount of information available in the open literature on machining maraging steel is limited to either turning [10] or individual surface integrity aspects in grinding (e.g. phase transformation [11]. The present work aims at investigating the effects of grinding force, grinding temperature and grinding parameters (grinding speed, workpiece speed, grinding depth on the surface and in-depth residual stress 
distributions induced by grinding of $3 \mathrm{~J} 33$ maraging steel the miniature electroplated $\mathrm{CBN}$ wheels.

\section{Material and experimental procedure}

\subsection{Material and specimen preparation}

3J33 maraging steel used in this study is ductile in the solution treated condition and attains ultrahigh tensile strength after aging at the range of $454 / 510{ }^{\circ} \mathrm{C}$. The chemical composition listed in Tables 1.

All specimens were cut and squared off to dimensions of $20 \times 15 \times 2 \mathrm{~mm}$ from $25 \mathrm{~mm}$ diameter forged bars. A total of twelve specimens were employed, as shown in Fig. 2.The measurement of the residual stresses shows that all specimens have practically the same pre-existing residual stress $( \pm 70 \mathrm{MPa})$. These values are considered as the initial condition of the material stress state before grinding operations.

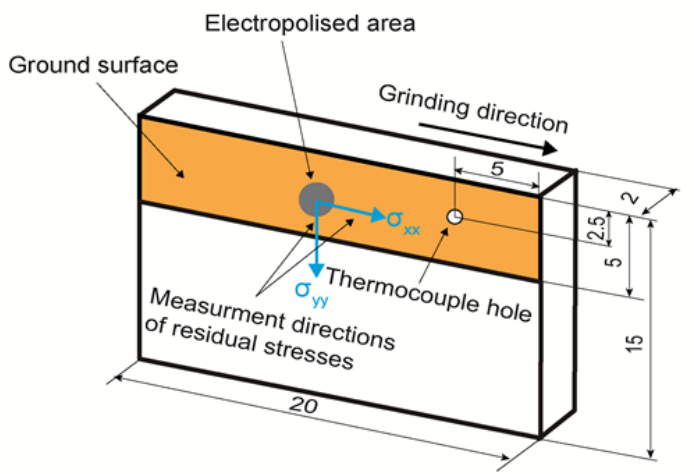

Fig. 1. Specimen scheme and residual stresses measurement directions.

Table 1. Chemical composition of $3 \mathrm{~J} 33$ maraging steel (wt \%).

\begin{tabular}{cccccccccccc}
\hline $\mathrm{C}$ & $\mathrm{Ni}$ & $\mathrm{Mn}$ & $\mathrm{Mo}$ & $\mathrm{Co}$ & $\mathrm{Ti}$ & $\mathrm{Al}$ & $\mathrm{Mn}$ & $\mathrm{Si}$ & $\mathrm{S}$ & $\mathrm{P}$ & $\mathrm{Fe}$ \\
\hline 0.001 & 18.45 & 0.02 & 4.76 & 8.98 & 0.65 & 0.09 & 0.02 & 0.03 & 0.001 & 0.003 & Bal. \\
\hline
\end{tabular}

Table 2. Summary of grinding trials and their introduced grinding forces and temperature.

\begin{tabular}{ccccccc}
\hline Test & $\mathrm{V}_{\mathrm{s}}$ & $\mathrm{V}_{\mathrm{w}}$ & $\mathrm{a}_{\mathrm{p}}$ & $\mathrm{F}_{\mathrm{t}}(\mathrm{N})$ & $\mathrm{F}_{\mathrm{n}}(\mathrm{N})$ & $\mathrm{T}\left({ }^{\circ} \mathrm{C}\right)$ \\
\hline 1 & 5.03 & 10.5 & 4 & 1.31 & 1.52 & 59.9 \\
2 & 7.54 & 10.5 & 4 & 1.03 & 1.17 & 65.2 \\
3 & 10.05 & 10.5 & 4 & 0.89 & 1.05 & 71.9 \\
4 & 12.57 & 10.5 & 4 & 0.73 & 0.93 & 84.2 \\
5 & 7.54 & 5.25 & 2 & 0.52 & 0.63 & 52.2 \\
6 & 7.54 & 10.5 & 2 & 0.76 & 0.92 & 56.5 \\
7 & 7.54 & 15.75 & 2 & 0.92 & 1.08 & 60.9 \\
8 & 7.54 & 18.35 & 2 & 1.05 & 1.23 & 65.5 \\
9 & 10.05 & 10.5 & 1 & 0.22 & 0.30 & 44.1 \\
10 & 10.05 & 10.5 & 2 & 0.33 & 0.44 & 48.4 \\
11 & 10.05 & 10.5 & 3 & 0.62 & 0.81 & 58.2 \\
\hline
\end{tabular}

\subsection{Experimental design}

In the present research, three process parameters, namely wheel speed $\left(\mathrm{V}_{\mathrm{c}}\right)$, workpiece speed $\left(\mathrm{V}_{\mathrm{w}}\right)$ and grinding depth $\left(a_{p}\right)$, were selected as independent factors with four levels. A single-factor experimental design was used to investigate the effects of grinding force, grinding temperature and grinding parameters (grinding speed, workpiece speed, and grinding depth) on the surface and in-depth residual stress distributions. The specific experiment scheme and results of grinding force and temperature are shown in Table 2.

\subsection{Experimental setup}

The grinding set-up in this study is shown in Fig. 2(a).A high-precision Vertical $\mathrm{CNC}$ Machining Center employing a spindle with a maximum speed of 30000 $\mathrm{rev} / \mathrm{min}$ was employed in this study. Electroplated $\mathrm{cBN}$ grinding wheel (wheel diameter $=15 \mathrm{~mm}$, face width $=$ $10 \mathrm{~mm}$, shank diameter $=10 \mathrm{~mm}$, shank length $=15 \mathrm{~mm}$ ) was submitted to grinding of specimens in an up-grinding mode under dry environment. The optical observation of the grinding wheel indicated that tool wear was very slight. Therefore, the effect of tool wear on residual stresses can be neglected and all the evaluated experimental results are based on the fresh grinding wheels.

The grinding forces, including normal force $F_{n}$ and tangential force $F_{t}$, were measured using Kistler piezoelectric dynamometer (model 9256C2). The grinding forces signal generated at the dynamometer was amplified using Kistler 5080A charge amplifier. The amplified signal was acquired and sampled using a data recorder (LMS SCR05) and stored in computer using Matlab software for further analysis. The sampling frequency of data was kept at $1 \mathrm{kHz}$ per channel and the average value of steady-state force was used in the analysis. The measurement of grinding temperature was conducted by a two-wire grindable thermocouple (type K, with $0.25 \mathrm{~mm}$ diameter).

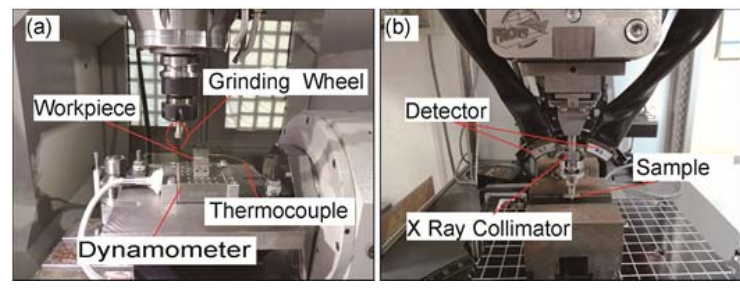

Fig. 2. Experimental setup:(a)machine tool;(b)X-ray stress analyser. 


\subsection{Residual stress measurement methodology}

The in-depth residual stress profiles of the ground samples were determined by X-ray diffraction using the $\sin 2 \psi$ technique and 10 tilt angles $\left(\psi= \pm 25^{\circ}, \pm 20^{\circ}\right.$, $\left.\pm 15^{\circ}, \pm 10^{\circ}, 0^{\circ}, 30^{\circ}\right)$ were selected. $\mathrm{Cr}-\mathrm{K} \alpha$ radiation was used to determine the elastic strains in the $\left\{\begin{array}{lll}2 & 1 & 1\end{array}\right\}$ lattice planes (diffraction peak $2 \theta=156^{\circ}$ ). The X-ray elastic constants, S1 and $1 / 2 \mathrm{~S} 2$, needed for the stress calculations are $1.27 \times 10-6 \mathrm{MPa}-1$ and $5.61 \times 10-6 \mathrm{MPa}-1$ for measured $\alpha-\mathrm{Fe}\left\{\begin{array}{lll}2 & 1 & 1\end{array}\right\}$ diffraction planes.

The residual stresses were measured in parallel $\left(\sigma_{\mathrm{xx}}\right)$ and perpendicular $\left(\sigma_{\mathrm{yy}}\right)$ to the grinding direction (see Fig. 1) using Canada PROTO-LXRD X-ray stress analyzer (Fig. 2(b)) equipped with commercial X'Pert Stress Plus software including the database of material's constants. The near central area of ground samples was taken as the location for measurement (see Fig. 1).The PROTO Electropolisher (Model 8818-V3) was used for residual stress with depth determination by removing layers with steps between 1 and $15 \mu \mathrm{m}$.

\section{Results and discussion}

\subsection{Results and general observation}

The in-depth residual stress distributions of all test samples were measured. Typical residual stresses distribution profile after grinding is shown in Fig. 3. For all of the samples, the residual stresses at the ground surface are compressive with values ranging from -180 to $-300 \mathrm{Mpa}$ in the grinding direction $\left(\sigma_{x x}\right)$ and -340 to -500 $\mathrm{MPa}$ in the transverse direction $\left(\sigma_{y y}\right)$ depending upon the cutting parameters employed. Moreover, the profiles and characters of the residual stresses distribution are similar and present as a hook shape; i.e., with increasing depth beneath the ground surface the compressive stress rapidly drops to maximum and slowly rises in a compressive state until returning to the original bulk values value $( \pm 70$ Mpa). The results also showed that, at any measured position, residual stresses in the grinding direction $\left(\sigma_{x x}\right)$ were found to be least compressive than those in the transverse direction $\left(\sigma_{y y}\right)$, in other words, the residual stresses of these two directions were found to fulfill the condition $\left(\sigma_{x x}\right)-\left(\sigma_{y y}\right)>0$. This phenomenon is attributed to the fact that the produced grinding temperature is generally below $90{ }^{\circ} \mathrm{C}$ throughout the experimental domain which indicates that the mechanical effect plays the dominating role in the formation of grinding-induced residual stresses.

Since the profiles follow the same trend in both the parallel and transverse of the grinding direction, the residual stresses distribution in grinding direction is only discussed in this paper.

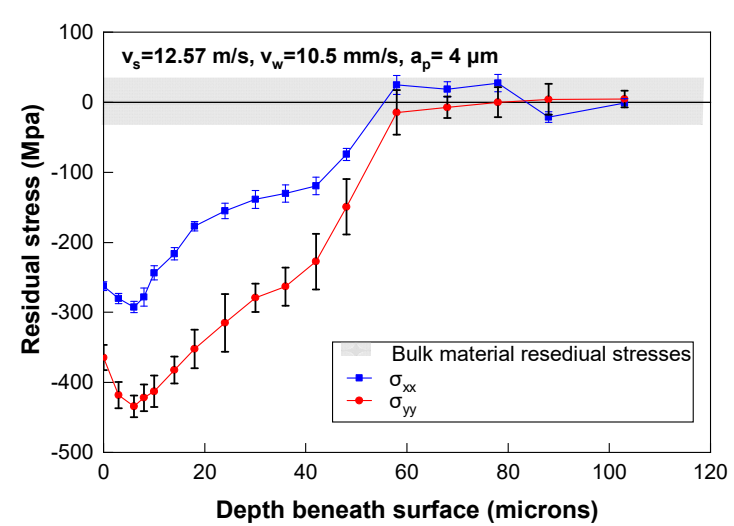

Fig. 3. typical residual stresses profile in grinding of $3 \mathrm{~J} 33$ maraging steel.

To quantitively describe and investigate the compressive residual stress distributions, four characteristic parameters have been named and studied: $\sigma_{\mathrm{s}}$, the compressive residual stress at the surface (MPa); ocomp,max, the maximum value of the compressive residual stress (MPa); $Z_{\mathrm{mc}}$, the distance of $\sigma_{\text {comp,max }}$ from the surface $(\mu \mathrm{m}) ; Z 0$, the depth of residual stresses $(\mu \mathrm{m})$.

\subsection{Grinding force, temperate and their correlation with residual stresses}

Residual stresses are developed when a workpiece is subjected to inhomogeneous deformation throughout its section. The causes for residual stresses in ground workpiece are majorly from mechanical deformation, thermal expansion, and contraction and material phase transformation [12]. The balance between these three different mechanisms defines whether the final residual stresses are compressive or tensile [13]. If the amount of tensile deformation produced is greater than the level of compressive deformation then compressive residual stresses will be produced and vice verse [14]. In general, the grinding force and temperature can be highly related to the residual stresses distribution in a ground part.

The values surface residual stresses $\left(\sigma_{\mathrm{s}}\right)$ and maximum compressive residual stresses $\left(\sigma_{\text {comp,max }}\right)$ that induced in each test are plotted against the grinding force and temperature in Fig. 4 and Fig. 5 respectively. As shown in Fig. 4, it is seen that both surface residual stresses and maximum compressive residual stresses have good correlation with cutting force and they are decreased with the increase in grinding force in the current investigation. This is because high grinding force also means high grinding temperatures which generate greater thermal plastic deformation contributing to the reduction of compressive residual stresses. 


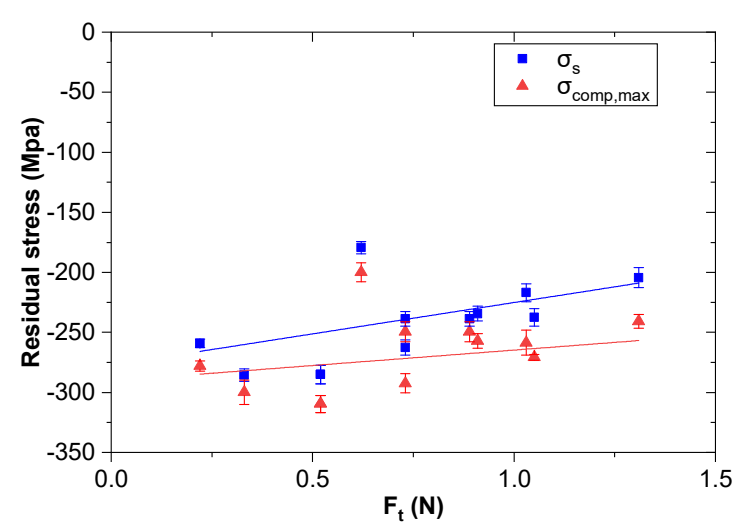

Fig. 4. Effect of grinding force on $\sigma_{\mathrm{s}}$ and $\sigma_{\text {comp,max }}$

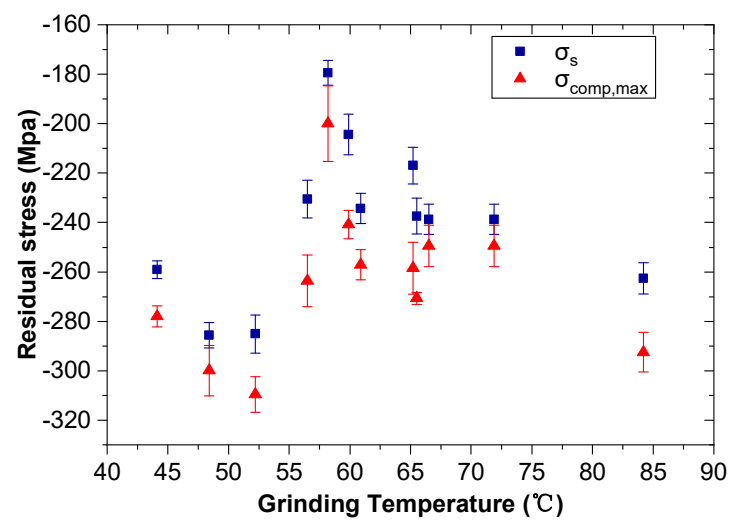

Fig. 5. Effect of grinding temperature on $\sigma_{\mathrm{s}}$ and $\sigma_{\text {comp,max. }}$

As opposed to the clear tendencies observed for grinding force, surface residual stresses and maximum compressive residual stresses do not show well-defined tendencies in relation to grinding temperature (Fig. 4). This is inconsistent with what most researchers have found. A number of authors have reported that the residual stress in grinding increases with increase in grinding zone temperature till about $700 \mathrm{C}$ for steel [15] .It is likely attribute to the fact that the grinding temperature is much lower than that in conventional grinding. Within the range of grinding conditions investigated, the effect of the grinding temperature on residual stress is less important than the grinding force. In other words, the variance in the physical properties of the machined surface is attributed mainly to the plastic deformation resulted from the grinding pressure.

\subsection{Effect of cutting parameters on surface residual stresses}

\subsubsection{Influence of grinding speed}

The effect of grinding speed variation on residual stresses distribution was investigated for a workpiece speed of $10.5 \mathrm{~mm} / \mathrm{s}$ and for a grinding depth of $4 \mathrm{um}$. Fig. 6 gives the residual stresses distribution profiles in the grinding direction when the grinding speed varies from 5.03 to $12.57 \mathrm{~m} / \mathrm{s}$.
The characteristic parameters of the residual stresses profiles under different grinding speed are detailed in Table 3.It can be seen that the higher the grinding speed, the bigger the surface compressive residual stress. Results show an increase of $-58 \mathrm{MPa}$ in the surface compressive residual stress when the grinding speed increased from 5.03 to $12.57 \mathrm{~m} / \mathrm{s}$. The same kind of trend is also obtained for parameter $\sigma_{\text {comp,max }}$ and $\mathrm{Z}_{\mathrm{mc}}$. For example, for $\mathrm{Vs}=5.03 \mathrm{~m} / \mathrm{s}$, the parameter $\sigma_{\text {comp,max }}$ equal to about $-240 \mathrm{MPa}$ is obtained while for $\mathrm{Vs}=12.57 \mathrm{~m} / \mathrm{s}$, the $\sigma_{\text {comp,max }}$ reaches about $-292 \mathrm{MPa}$. This trend is expected because the chip flow rate increases with the increase of grinding speed. Higher chip flow rates will increase the amount of thermal energy evacuated in the chip. This reduces the effect of the thermal load on the workpiece and therefore mechanical effects dominate, resulting in a more compressive residual stress regime. However, the depth of residual stresses $\left(Z_{0}\right)$ decreased with the cutting speed. If these results are linked to cutting forces, analysis shows that both the cutting force and feed force tend to diminish as the cutting speed increases (Table 2).

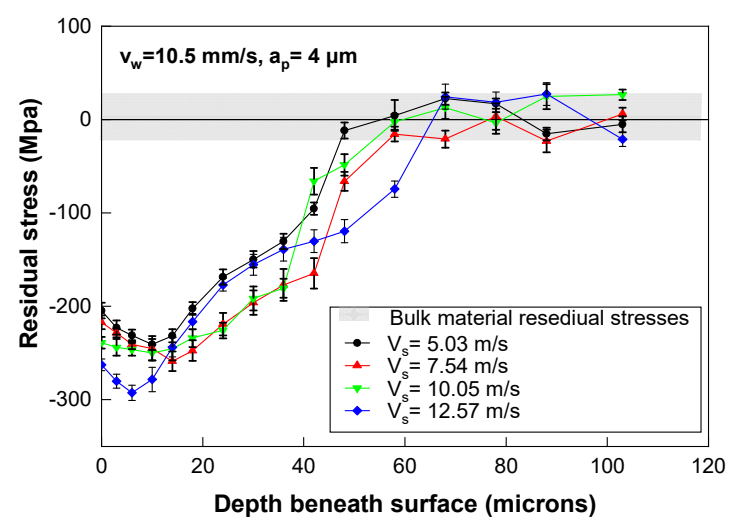

Fig. 6. Residual stresses distribution with different grinding speed.

Table 3.Effect of the grinding speed on the characteristic parameters of the residual stresses analysis for $\mathrm{Vw}=10.5 \mathrm{~mm} / \mathrm{s}$ and ap $=4 \mu \mathrm{m}$.

\begin{tabular}{ccccc}
\hline Vs & \multicolumn{2}{c}{ Residual stresses } & \multicolumn{2}{c}{ grinding-affected depth } \\
\cline { 2 - 5 } & $\sigma_{\mathrm{s}}$ & $\sigma_{\text {comp,max }}$ & $\mathrm{Z}_{\mathrm{mc}}$ & $\mathrm{Z}_{0}$ \\
\hline 5.03 & -204 & -240 & 10 & 42 \\
7.54 & -216 & -258 & 14 & 48 \\
10.05 & -238 & -249 & 10 & 58 \\
12.57 & -262 & -292 & 6 & 58 \\
\hline
\end{tabular}

\subsubsection{Effect of workpiece speed on residual stresses}

The residual stresses vary with the workpiece speed as shown in Fig. 7. It can be seen that the value of parameter $\sigma_{\mathrm{s}}$ and $\sigma_{\text {comp,max }}$ basically appear stable state regardless of the variation of workpiece speed in the range of $10.5-18.35 \mathrm{~mm} / \mathrm{s}$. However, an obvious decrease in the value of these parameters can be observed when 
workpiece speed increased from 5.25 to $10.5 \mathrm{~mm} / \mathrm{s}$. This can be explained considering that an increasing value of workpiece speed leads to an augmentation of the grinding temperature (Table. 2). it also can be seen from table 4 that the workpiece speed has slight effect on the the value of parameter $Z_{m c}$ and $Z_{0}$ since the variation of the residual stresses is approximate to $3 \mu \mathrm{m}$.

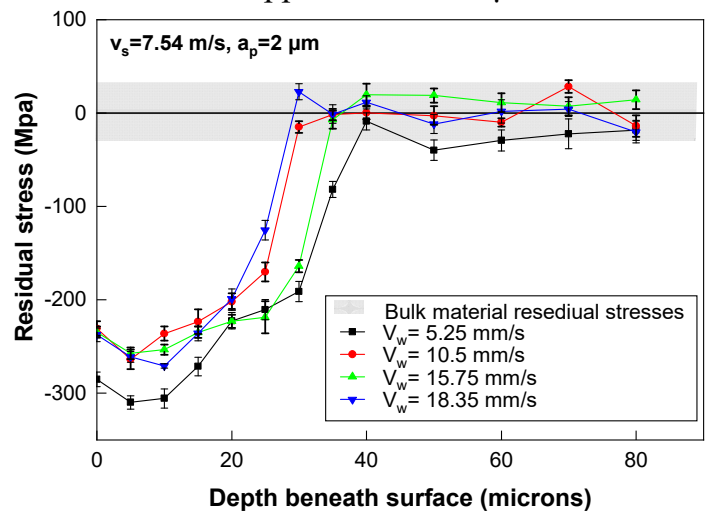

Fig. 7. Residual stresses distribution in the grinding direction with different workpiece speed.

Table 4. Effect of the workpiece speed on the characteristic parameters of the residual stresses analysis for Vs $=7.54 \mathrm{~m} / \mathrm{s}$ and ap $=2 \mu \mathrm{m}$.

\begin{tabular}{ccccc}
\hline $\mathrm{V}_{\mathrm{w}}$ & \multicolumn{2}{c}{ Residual stresses } & \multicolumn{2}{c}{ grinding-affected depth } \\
\hline & $\sigma_{\mathrm{s}}$ & $\sigma_{\text {comp,max }}$ & $\mathrm{Z}_{\mathrm{mc}}$ & $\mathrm{Z}_{0}$ \\
\hline 5.25 & -285 & -309 & 3 & 28 \\
10.5 & -230 & -263 & 3 & 24 \\
15.75 & -234 & -257 & 3 & 24 \\
18.35 & -237 & -270 & 6 & 18 \\
\hline
\end{tabular}

\subsubsection{Effect of grinding depth on residual stresses}

The residual stresses distributions with different depths of cut are plotted in Fig. 8 and their characteristic parameters are detailed in table 5 .

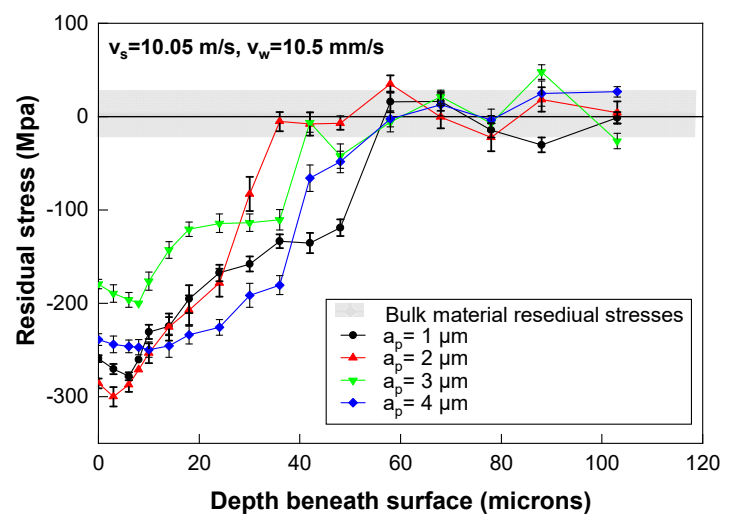

Fig. 8. Residual stresses distribution in the grinding direction with grinding depth.
Table 5. Effect of the grinding depth on the characteristic parameters of the residual stresses analysis for $\mathrm{Vs}=10.05 \mathrm{~m} / \mathrm{s}$ and $\mathrm{Vw}=10.5 \mathrm{~mm} / \mathrm{s}$.

\begin{tabular}{|c|c|c|c|c|}
\hline $\mathrm{a}_{\mathrm{p}}$ & \multicolumn{2}{|c|}{ Residual stresses } & \multicolumn{2}{c|}{ grinding-affected depth } \\
\hline & $\sigma_{\mathrm{s}}$ & $\sigma_{\text {comp,max }}$ & $\mathrm{Z}_{\mathrm{mc}}$ & $\mathrm{Z}_{0}$ \\
\hline 1 & -259 & -277 & 6 & 30 \\
\hline 1 & -285 & -299 & 3 & 30 \\
\hline 3 & -179 & -200 & 8 & 36 \\
\hline 4 & -238 & -249 & 10 & 58 \\
\hline
\end{tabular}

The value of the parameter $\sigma_{\mathrm{s}}$ and $\sigma_{\text {comp,max }}$ in the grinding direction is in the ranges of -179 to $-285 \mathrm{MPa}$ and -200 to $-299 \mathrm{MPa}$, respectively. As can be seen from table 5 , there is no obvious correlation between these parameters and the grinding depth. However, with the increase in grinding depth, the depth of residual stresses $\left(Z_{0}\right)$ is also increased. This can be due to the fact that a decrement of depth of cut is equivalent to a diminution of thickness of cut.

\section{Conclusions}

This paper presents the findings of an experimental investigation of surface and in-depth residual stress distributions induced by grinding of $3 \mathrm{~J} 33$ maraging steel with the miniature electroplated $\mathrm{CBN}$ wheels. The distributions of residual stresses over the ground surface layer were measured in an X-ray diffraction apparatus using the $\sin 2 \psi$ method with step-by-step electrolytic dissolution, and then studied quantitatively. The following conclusions are drawn.

(1) Grinding of 3J33 maraging steel with miniature electroplated CBN wheel generated "hook" shaped compressive residual stresses distribution under the experimental conditions.

(2) The surface residual stresses in the transverse grinding direction are much more compressive than that in the grinding direction. On the whole, the main cutting parameters affecting the distribution of residual stresses are the grinding speed, while the workpiece speed and the grinding depth has the least effect on surface residual stresses.

(3) There is a good correlation between residual stress and cutting force, but the trend related to grinding temperature is not obvious.

The paper quantitatively studies the distribution characteristics of the residual stress in grinding of $3 \mathrm{~J} 33$ maraging steel. In the future, in order to improve the service life and control the deformation of the component, more attention should be paid to the precise adjustment of the distribution of residual stress by optimizing the machining parameters and process sequence.

The authors would like to acknowledge the funding support to this research from the National Natural Science Foundation of China (Grant No.: 51675096).

\section{References}


1. P. Venkata Ramana a, G. Madhusudhan Reddy, T. Mohandas, A.V.S.S.K.S. Gupta, Mater. Des. 31,749 (2010)

2. M.J. Balart, A. Bouzina, L. Edwards, M.E. Fitzpatrick, Mater. Sci. Eng. A 367,132 (2004)

3. Yamin Shao, Omar Fergani,Beizhi Li, Steven Y. Liang, Int. J. Adv. Manuf. Technol. 83,743 (2016)

4. Jianbin Chen, Qihong Fang, Liangchi Zhang, Int. J. Adv. Manuf. Technol. 75,615 (2014)

5. Ding Wenfeng, $\mathrm{Xu}$ Jiuhua, Chen Zhenzhen, $\mathrm{Su}$ Honghua, Fu Yucan, Chin. J. Aeronaut. 23,501 (2010)

6. E. Brinksmeier, J. T. Cammett, W. Konig, P. Leskovar, J. Peters, H. K. Tonshoff, CIRP Ann-Manuf. Technol. 31,491 (1982)

7. A.D. Sosa, M.D. Echeverría, O.J. Moncada, J.A. Sikora, Int. J. Mach. Tools Manuf. 47,229 (2007)
8. Brahim Ben Fathallah, Nabil Ben Fredj, Habib Sidhom, Chedly Braham, Yoshio Ichida, Int. J. Mach. Tools Manuf. 49,261 (2009)

9. Hédi Hamdi, Hassan Zahouani, Jean-Michel Bergheau, J. Mater. Process. Technol. 147,277 (2004)

10. M. Santhanakumar, R. Adalarasan, S. Siddharth, A. Velayudham, J. Braz. Soc. Mech. Sci. Eng. 39,2071 (2017)

11. Zishan Ding, Beizhi Li, Steven Y. Liang, Mater. Lett. 154,37 (2015)

12. X. Chena, W.B. Roweb, D.F. McCormack, J. Mater. Process. Technol. 107,216 (2000)

13. Mofid Mahdi, Liangchi Zhang, Int. J. Mach. Tools Manuf. 39,1285 (1999)

14. A.R.C. Sharman, J.I. Hughes, K. Ridgway, J. Mater. Process. Technol. 173,359 (2006)

15. S. Malkin, C. Guo, CIRP Ann-Manuf. Technol. 56,760 (2007) 